\title{
Density Distribution and Resin Migration Investigations in Samples of Sand Core Made by Blowing Method
}

\author{
Rafał Dańko $^{a *}$, Łukasz Jamrozowicz $^{\mathrm{a}}$ \\ ${ }^{a}$ AGH University of Science and Technology, Faculty of Foundry Engineering, Reymonta 23, 30-059 Krakow, Poland \\ *e-mail:rd@agh.edu.pl
}

Received: 1 September 2017/Accepted: 15 October 2017/Published online: 9 November 2017

This article is published with open access at AGH University of Science and Technology

\begin{abstract}
Resin migration in a core can occur during the core production process performed by blowing methods in which the core sand is transported into the core box as a two-phase sand-air flux characterized by various working parameters (working pressure, shooting time, volumetric concentration). This migration is the result of the resin being blown off from the matrix grain surfaces by compressed air. The methodology of the investigation of this effect developed at AGH University of Science and Technology is presented in this paper. The results of the resin migration tests obtained for cores made with cold-box technology at various working parameters of the shooting process are also shown.
\end{abstract}

\section{Keywords:}

core shooting, core blowing, molding sand, resin migration

\section{INTRODUCTION}

The blowing process [1-8] of molding sand compaction and its hardening (during which, a sand-air flux is introduced into a mold cavity and followed by successive flows of air and a hardening factor - one after another - into venting holes) is burdened with at least two disadvantages. The first one constitutes the diversification of the molding sand compaction within the core volume, especially visible when the sand is shot through individual shooting holes, since it leads to a significantly higher apparent density in the shooting hole axis. The second disadvantage is resin migration under the influence of air flux. This air flux is filtered via the porous medium into the venting holes.

It can be assumed that both aspects occur in all varieties of the core production technology based on shooting molding sands with liquid resins, hardened by gaseous factors. These aspects are especially important for sands with binders with a low viscosity, which characterizes, among others, the classic cold box technology (Ashland process). This is the subject of our investigations.

The discussed process is based on producing cores with the application of a gaseous hardener. The core sand contains 100 parts by weight of sand, $0.4-0.8$ parts by weight of polyalcohol-benzyl-ether, and 0.4-0.8 parts by weight of polyisocyanate. Both the resin and polyisocyanate are low-viscosity liquids, usually mixed at a ratio of $1: 1$. This mixture reacts in the presence of the proper amino-catalyst blown through the core sand. The resin polymerization occurs in a few seconds. At the end of the hardening reaction, the unused amine shifts itself to successive sand portions and catalyzes their reaction. After the total core hardening, amine is rinsed out by the cleaning air and then transferred to a neutralizing washer filled with sulfuric acid.

\section{INVESTIGATIONS}

The standard high-silica sand (100 parts by weight) from the Grudzeń-Las mine was used as the matrix in our investigations. For preparation of the molding sands, the phenol-formaldehyde resin ( 0.8 parts by weight) of the trade name Gasharz 6966 from the Hüttenes Albertus Company was applied. The second component of this binder was polyisocyanate ( 0.8 parts by weight) of the trade name Aktywator 7624 from the same company. As the catalyst of the reaction between both binder components, dimethyl-ethyl-amine (DMEA) was applied in the preparations of the cores, while amine of the trade name Katalizator GH3 was used in the investigations.

Core sands were prepared in a laboratory paddle mixer (type LM-R1). The core sand portion was $5 \mathrm{~kg}$ each time, which warranted the proper mixing of the components. The mixing time was $3 \mathrm{~min}$. To begin with, the sand with the first part of the binder was mixed for 1.5 min.; then, the second part of the binder was added and mixed for the next $1.5 \mathrm{~min}$.

The shaped elements on which the tests were performed were made by the experimental blower shown in Figure 1. The blowing machine is equipped with shooting chambers with a volume of 2.2 liters. The shooting chambers are equipped with heads that have three blowing nozzles (each of a diameter of $11 \mathrm{~mm}$ ) and venting stoppers. 


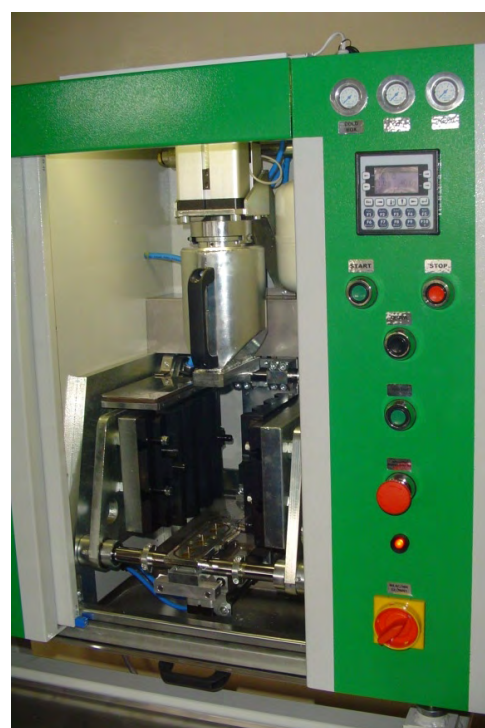

Fig. 1. Research stand with blowing machine

Due to the upper air supply (above the sand), it should be assumed that it meets the classification criteria concerning the blower and realizes the blowing process. The application of the experimental core box (Fig. 2) allowed us to make the shaped elements destined for testing the resin migration. The measurements were performed on the longitudinal shaped elements of dimensions $22.5 \times 22.5 \times 167 \mathrm{~mm}$ prepared on a research stand. Three shaped elements were made in one cycle. a)

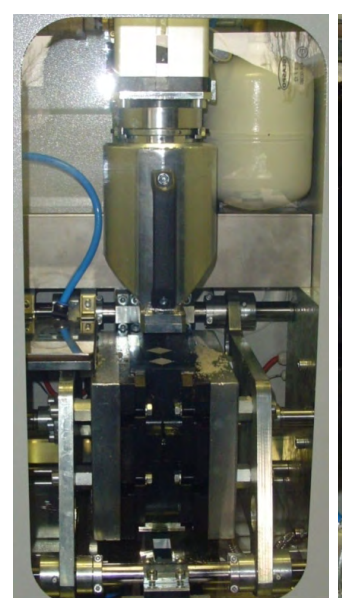

b)

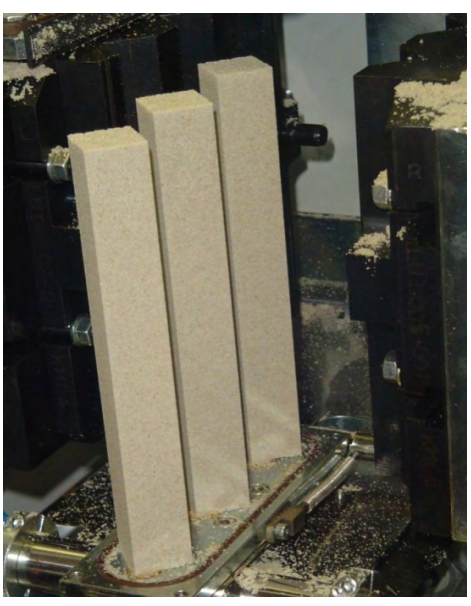

Fig. 2. Core box (a) and shaped elements (b) made of core sand

The prepared core sand was blown into the core box at air pressures $(p)$ of $0.40,0.45,0.50$, and $0.55 \mathrm{MPa}$ while applying the following blowing times in each series: $0.5,1.0$, and 1.5 seconds. After core compaction, the gaseous catalyst was blown through the core with a pressure of $0.15 \mathrm{MPa}$. The time of blowing was 3 seconds. The amount of amine blown into the core box was approximately $1.7 \mathrm{~cm}^{3} /$ cycle (for $420 \mathrm{~g}$ of core sand). After hardening, the cores were blown through by air for 17 seconds.

Measuring of the resin migration was performed as follows: compacted and hardened shaped elements made out of the core sand were cut into 7 pieces with similar dimensions. The way of dividing these shape elements is presented in Figure 3. Then, each sample was crushed and weighed. Sample elements prepared in such a way were roasted in an M14 sylite furnace at a temperature of $850^{\circ} \mathrm{C}$ for 1 hour. After cooling, the sample was weighed again, and then the resin content was calculated according to equation [3]:

$$
M=\frac{m_{0}-m_{1}}{m_{0}} \times 100 \%
$$

where:

$$
\begin{aligned}
& M \text { - } \\
& \text { resin content in the given part of the shaped } \\
& \text { element, \%; } \\
& m_{0}-\text { sample mass before roasting, } \mathrm{g} ; \\
& m_{1}-\text { sample mass after roasting, } \mathrm{g} .
\end{aligned}
$$

a)

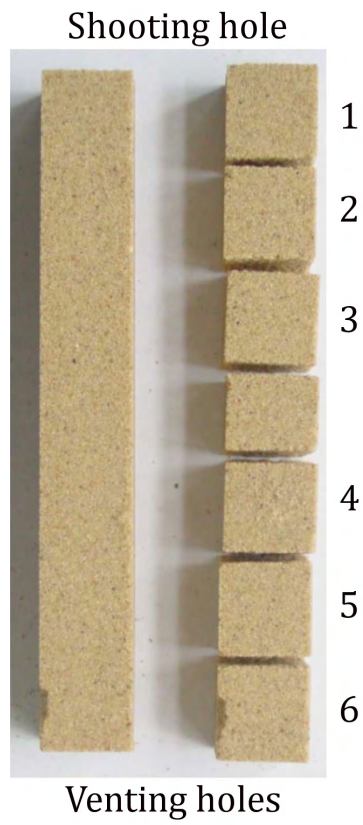

b)

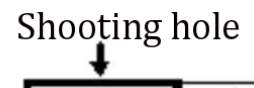

Fig. 3. Method of dividing sample of dimensions $22.5 \times 22.5 \times 167 \mathrm{~mm}$ into elements for apparent density and binder content measurements: a) view of cut sample; b) scheme of division

The second testing series concerned the core sand apparent density measurements in the given piece of the shaped element. For this aim, the individual parts of the sample before crushing were measured by a slide caliper and weighed. The apparent density was calculated in the following way [3]:

$$
\rho=\frac{m}{a \times b \times c}
$$

where:

\footnotetext{
$\rho$ - apparent density of the core sand, $\mathrm{g} / \mathrm{cm}^{3}$;

$a, b, c$ - dimensions: width, thickness, height - respectively, cm;

$m$ - sample mass, g.
} 


\section{RESULTS AND ANALYSIS OF MEASUREMENTS}

The results of the resin content in the core sand sample at a pressure of $0.40 \mathrm{MPa}$ are shown in Figure 4. The binder content in the core sand should be $1.6 \%$ and should be the same throughout the whole core volume.

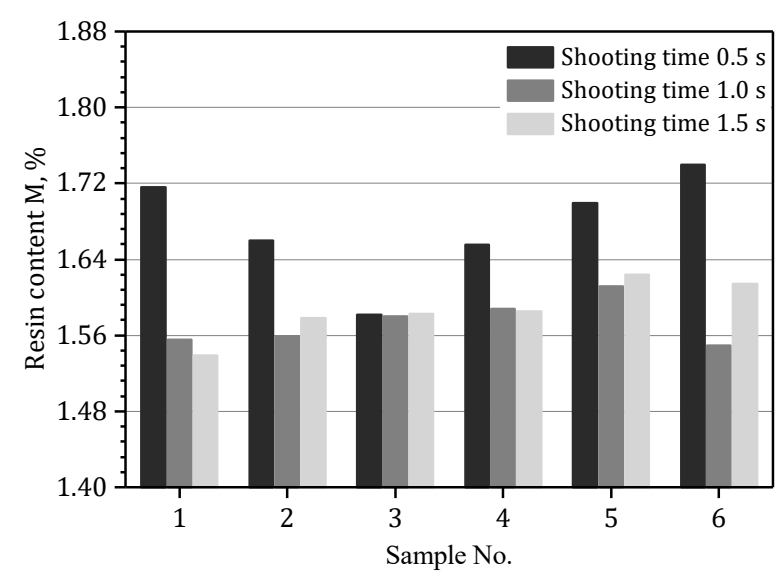

Fig. 4. Investigations of resin migration for core sand containing $1.6 \%$ resin, $p=0.40 \mathrm{MPa}$

Analyzing the diagram, it can be noticed that, for the shooting time of $0.5 \mathrm{~s}$, the smallest binder content occurs in the middle part of the shaped element (sample elements Nos. 3 and 4). For Sample No. 3, this does not even reach $1.6 \%$. Such a binder distribution causes a weakening in the shaped element middle part in the place where this element is most-susceptible to breaking. For shooting times of 1.0 and 1.5 seconds, the smallest amount of the binder occurs at both ends of the shaped element, which means at the shooting hole (Sample No. 1) and near the venting holes (Sample No. 2). Along with an increasing distance from the shooting hole, the binder content increases and achieves the maximum value in Sample No. 5 .

The binder distribution in the core sand is caused by the air introducing this sand into the core box. In dependence of the process realization, the air causes a tearing away of the binder part from the sand grains and transfers them to the porous core channels in accordance with the flow direction. The small amount of binder at the end of the shaped element is caused by blowing out liquid resin from the venting hole range where, due to the air expansion, its flow rate increases. It should be also noticed that the binder content is only higher than $1.6 \%$ in Sample No. 5, while it is smaller for the remaining samples.

The data given in Figure 5 indicates that, after increasing the shooting pressure to $0.45 \mathrm{MPa}$, the binder distribution at the core length observed in the shaped elements for a pressure of $0.40 \mathrm{MPa}$ and shooting times being 1.0 and 1.5 seconds, which is similar and occurs for all times of the core box filling. Certain differences can be found when the binder content in Sample No. 1 will be compared for both pressure values. In the case of the pressure of $0.45 \mathrm{MPa}$, the binder amount is lower by approximately $0.04 \%$. A similar situation concerns the remaining samples.
Only in Sample No. 5 does the binder content exceed 1.6\%; this is comparable with the amount obtained for the pressure of $0.40 \mathrm{MPa}$.

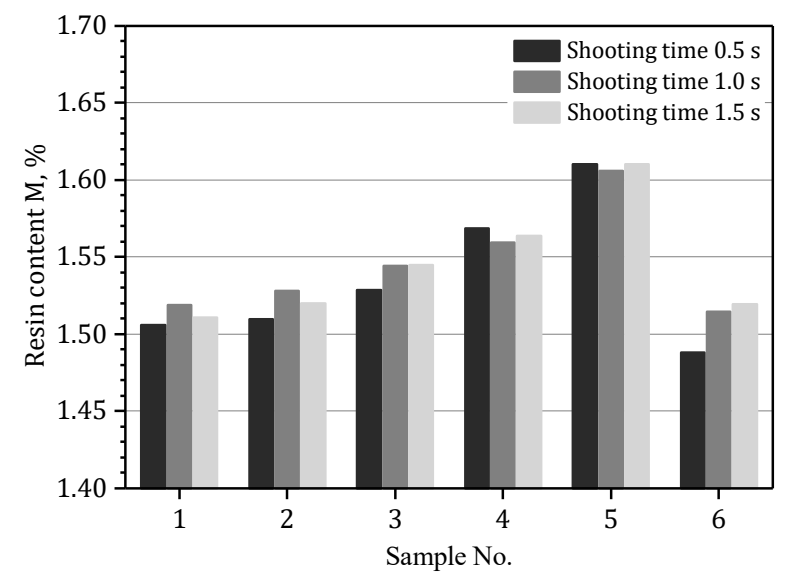

Fig. 5. Results of binder migration testing in longitudinal sample for core sand containing $1.6 \%$ resin, $p=0.45 \mathrm{MPa}$

The blowing of the core sand with a pressure of $0.50 \mathrm{MPa}$ caused a similar binder distribution in the longitudinal sample. However, for a blowing time of 0.5 seconds, an increase of the binder content occurs nearer the shooting hole in Sample No. 4 while, for other times, it occurs in Sample No. 5. The binder content for this pressure is also lower in the individual samples than for pressures of 0.40 and $0.45 \mathrm{MPa}$. It should also be emphasized that, for a shooting time of 1.5 seconds, the binder content in Sample No. 1 is less than $1.5 \%$. An analysis of the distribution of core sand compaction in the individual samples indicates that this distribution is uneven. The highest compaction occurs in the middle of the shaped element (Sample Nos. 3 and 4), while the lowest is at the ends (Sample Nos. 1 and 6).

The results of the investigations presented in Figure 6 indicate that the binder distribution on the core length is similar to the previous cases for shooting times of 0.5 and 1.0 seconds; i.e., the smallest binder amounts are at the ends of the shaped element (Sample Nos. 1 and 6).

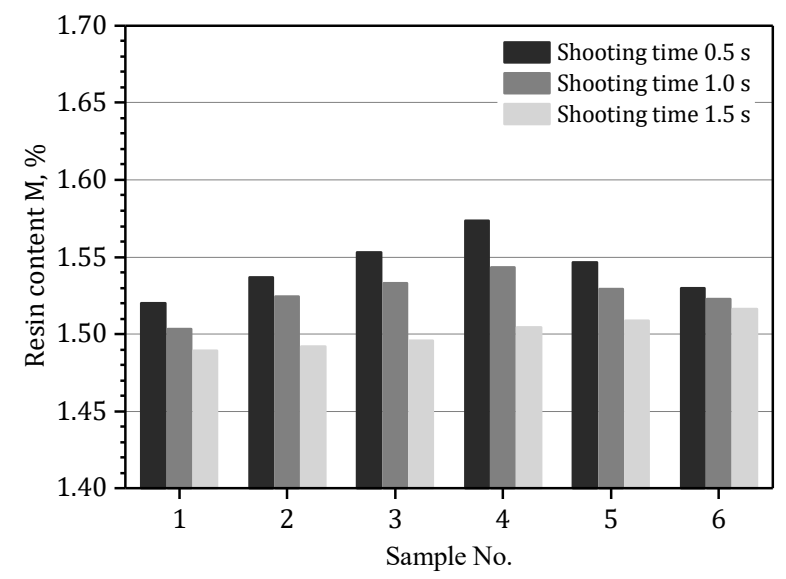

Fig. 6. Results of resin migration tests in longitudinal sample for core sand containing $1.6 \%$ resin, $p=0.55 \mathrm{MPa}$ 
The binder content increase (for these times) also occurs in Sample No. 4; however, its maximum value does not exceed $1.6 \%$. A different binder distribution occurs for a shooting time of 1.5 seconds. In this case, the smallest binder content occurs at the shooting hole (Sample No. 1) and increases with an increasing distance from this hole. The highest binder content occurs at the venting hole (Sample No. 6). The general binder content for a shooting pressure of $0.55 \mathrm{MPa}$ is the smallest when compared with the values obtained for lower blast pressures.

\section{CONCLUSIONS}

Summarizing the presented investigation results, it can be stated that, in the process of core production by blowing methods (blowing, shooting), the uneven distribution of sand compaction in the core is a reproducible effect. Regardless of the blowing pressure and blowing time, the highest compaction occurs in the blowing hole axis (middle of the core) and the lowest in places being at a distance from this axis. In the core ranges adjacent to the venting holes, a zone of better-compacted core sand occurs. The lower compaction degree of the sand at the core or sample ends forces an increased flow of the gas flux in the surface layers of the core due to the better permeability of the core sand being in these places.

The resin distribution in the shaped element (obtained by blowing the core sand into the core box), important for assessing the core sand strength, is not uniform but is subjected to certain regularities. The smallest amount of resin occurs in the part adjacent to the shooting hole, while the largest occurs in the vicinity of the venting holes. In addition, the influence of the shooting pressure on the resin content in the core sand is noticeable. It is especially visible for a shooting pressure of $0.55 \mathrm{MPa}$ (Fig. 6). Along with an increase of the air-blast working pressure as well as a blowing-time increase, the resin content decreases (which indicates that a certain resin amount is shifted to the surroundings by the air flux). The observed effect indicates the necessity of optimizing the blowing-process parameters in the direction of minimizing the working pressure and blowing time as well as the need for individual selection of these parameters for the given technology and core shape.

\section{Acknowledgements}

This work was supported by Polish NCN project UMO2014/15/B/ST8/00206.

\section{REFERENCES}

[1] Bakhtiyarov S.I., Overfelt R.A. (2003). CFD modeling and experimental study of resin-bonded sand/air two-phase flow in sand core making process. Powder Technology, 133, 68-78.

[2] Ni C., Guo E., Zhang Q., Jing T. \& Wu J. (2016). Frictional-kinetic modeling and numerical simulation of core shooting process. International Journal of Cast Metals Research, 29, 214-221.

[3] Dańko J. (1995). An effect of the venting system on the core box filling ratio and the apparent core density structure. Przegląd Odlewnictwa, 3, 85-92.

[4] Dańko J., Zych J., Dańko R. (2009). Diagnostic methods of technological properties and casting cores quality. Archives of Metallurgy and Materials, 54(2), 381-391.

[5] Vidal V., Beauvais P., Leger-Delcourt E., Hossemand J.S., Sadon P. (2005). Pressure distribution during core production core blowing machines. Fonderie Fondeur D'Aujourd'Hui, 241, 12-20.

[6] Winartomo B., Vroomen U., Buhrig-Polaczek A., Pelzer M. (2005). Multiphase modelling of core shooting process. International Journal of Cast Metals Research, 18(1), 13-20.

[7] Wu J., Cui Y., Li W. (2002). Computer simulation of core-shooting process with two-phase flow. International Journal of Cast Metals Research, 15, 445-449.

[8] Ni C.J., Lu G.C., Zhang Q.D., Jing T., Wu T.J., Yang L.L., Wu Q.F. (2016). Influence of core box vents distribution on flow dynamics of core shooting process based on experiment and numerical simulation. China Foundry, 13(1), 22-26. 